\title{
Correlation and Path Coefficient Analysis of Quantitative and Qualitative Traits in Hybrid Sunflower (Helianthus annuus L.)
}

\author{
Ayon Alipatra $^{1^{*}}$, Hirak Banerjee ${ }^{2}$ and Debasis Mazumdar ${ }^{3}$ \\ ${ }^{1}$ Dr. Kalam Agricultural College, Bihar Agricultural University, Arrabari, \\ Kishanganj-855 107, Bihar, India \\ ${ }^{2}$ Regional Research Station (CSZ), Bidhan Chandra Krishi Viswavidyalaya, \\ Kakdwip-743 347, West Bengal, India \\ ${ }^{3}$ Department of Agriculture Statistics, Bidhan Chandra Krishi Viswavidyalaya, Mohanpur- \\ 741 252, West Bengal, India \\ *Corresponding author
}

\section{A B S T R A C T}

A study was undertaken at West Bengal, India with hybrid sunflower cv. Aditya, during winter season of 2011-12 and 2012-13 in a split-plot design with three levels of irrigation (main-plots) and seven levels of sulphur (sub-plots) with three replications. Among the

\begin{tabular}{|c|}
\hline Keywords \\
\hline $\begin{array}{l}\text { Correlation coefficient, } \\
\text { Hybrid sunflower, Path } \\
\text { analysis, Qualitative } \\
\text { traits, Quantitative traits }\end{array}$ \\
\hline Article Info \\
\hline $\begin{array}{l}\text { Accepted: } \\
\text { 06 September } 2018 \\
\text { Available Online: } \\
10 \text { October } 2018\end{array}$ \\
\hline
\end{tabular}
phenotypic traits evaluated, significant $(p \leq 0.01)$ and positive correlation were detected between WFSC and SI $(r=0.44)$, SEY $(r=0.58)$ and STY $(r=0.41)$; between SI and SEY $(\mathrm{r}=0.49)$ and STY $(\mathrm{r}=0.41)$; between SEY and STY $(\mathrm{r}=0.59, p \leq 0.01)$. Seed yield showed highest significant $(p \leq 0.01)$ positive correlation with TNU $(\mathrm{r}=0.670)$, TBU $(\mathrm{r}=$ $0.669)$ as well as with $\mathrm{AN}(\mathrm{r}=0.602)$. The $\mathrm{OC}$ had significant $(p \leq 0.01)$ positive correlations with LA $(r=0.874)$, OA $(r=0.909)$ and IV $(r=0.936)$, while significant negative correlations was observed with PA $(r=-0.905)$, SA $(r=-0.828)$ and SV $(r=-$ 0.929). Among the growth and yield components, BG (0.612) followed by NFSC $(0.579)$ and WFSC (0.577) exhibited highly positive direct effects on seed yield of hybrid sunflower. The standard regression equation showed that independent variables like total $\mathrm{N}$ uptake, plant height, available $\mathrm{N}$, weight of filled seeds/capitulum and seed index (100seed weight) had positive significant relationship with seed yield (dependent variable). The first two ordinates axes of CCA explained $100 \%$ of the total variance in the weighted averages for dominance of observed parameters with respect to the irrigation and fertilizer variables, while irrigation was more important than fertilizer.

\section{Introduction}

Sunflower (Helianthus annuus L.) holds a great promise in meeting out the shortage of edible oils in India with higher yield potential and healthy oil quality (Banerjee et al., 2014). India has the fourth largest area under sunflower (5.9 lakh ha) in the world and accounts for $2.5 \%$ of the world acreage. Its share in total world production is about $4.6 \%$ (4.3 lakh tonnes) with lowest average productivity of $736 \mathrm{~kg} / \mathrm{ha}$ during 2014-15 (Indiastat, 2017). Since introduction of this crop in India during 1970s, productivity has 
remained low as compared to world average productivity though the area under this crop has increased markedly (Ramulu et al., 2011). In West Bengal, 0.15 lakh ha of land is under sunflower producing 0.22 lakh tonnes, while the productivity is $1.48 \mathrm{t} / \mathrm{ha}$ (Indiastat, 2017). Though there have been considerable advancements in the productivity of oilseed crops in West Bengal, the total internal supply of edible vegetable oils in the State is always being less than ever increasing demand.

The productivity of this crop is constrained due to its cultivation in the soil with poor fertility and limited soil moisture. Sunflower sown in lines can benefit by irrigation, where irrigation is applied by providing channels in between two adjacent rows (Moitra et al., 2012). The adequate supply of fertilizer increases sunflower yield appreciably (Bhattacharyya et al., 2015). Fertilizer plays an inevitable and imperative role in determining oil content and oil quality of sunflower. Therefore, improved agrotechniques like use of improved cultivars (hybrids), adequate water and nutrient supply are the keys to achieve higher productivity of the crop even under fertile land situation.

Seed yield of sunflower, a complex dependent character, is contributed by a number of component characters. These components are related among themselves and also with yield either positively or negatively. Thus, direct selection of a cultivar for seed yield is often not very effective rather indirect selection based on some associated traits may be useful (Hassan et al., 2013). Understanding the nature of associations among traits is important for direct or indirect selection and consequently to improve the efficiency of selection gains in plant breeding programs (Shimelis and Hugo, 2011). Simple correlation analysis establishes the mutual associations of variables without regard to cause and effect. Path coefficient analysis is useful statistical procedures to estimate the magnitude and nature of associations between selection parameters (Mashilo et al., 2016). Hence, the purpose of this study was to determine the importance of traits associated with seed yield and oil quality of hybrid sunflower along with their inter-relationships.

\section{Materials and Methods}

The experiment was conducted during winter seasons of 2011-12 and 2012-13 on well drained alluvial soil (Entisols) at farmer's field of Madandanga village under Chakdaha block of Nadia district in West Bengal $\left(23^{\circ} 22.221\right.$ 'N latitude, $88^{\circ} 22.221^{\prime} \mathrm{E}$ longitude and 12.0 meters above mean sea level) under typical sub-tropical climate. Maximum and minimum temperature fluctuated between 33.9 and $10.1^{\circ} \mathrm{C}$ in winter $2011-2012$ and 36 and $6.9^{\circ} \mathrm{C}$ in winter 2012-2013. Relative humidity prevailed between 99 and $33 \%$ in winter 20112012, and 98 and 31\% in winter 2012-2013. The rainfall during the experimental period (November to March) was 68.8 (4 rainy days) and $18.2 \mathrm{~mm}$ (3 rainy days) in winter 20112012 and winter 2012-2013, respectively. Analysis of the samples $(0-30 \mathrm{~cm})$ showed that the soil of the experimental site was clay loam in texture, non-saline (EC $0.29 \mathrm{dS} / \mathrm{m}$ ) with $\mathrm{pH}$ 6.89 , organic carbon $0.42 \%$, available N 175.4 $\mathrm{kg} / \mathrm{ha}$, available P $27.5 \mathrm{~kg} / \mathrm{ha}$, available $\mathrm{K}$ $108.08 \mathrm{~kg} / \mathrm{ha}$, available $\mathrm{S} 27.0 \mathrm{~kg} / \mathrm{ha}$ and available B $1.89 \mathrm{~kg} / \mathrm{ha}$.

The experiment was laid out in split-plot design, assigning three irrigation levels $\left(\mathrm{I}_{30}\right.$, one irrigation at $30 \mathrm{DAS} ; \mathrm{I}_{30 / 60}$, two irrigations at 30 and $60 \mathrm{DAS} ; \mathrm{I}_{30 / 60 / 80}$, three irrigations at 30, 60 and 80 DAS) in the main plot and seven fertilizer treatments $\left[\mathrm{F}_{1}\right.$, Farmer fertilizer practice/ FFP (60-30-30 kg N-P $\mathrm{O}_{5} \mathrm{O}^{-}$ $\mathrm{K}_{2} \mathrm{O} / \mathrm{ha}$ ); $\mathrm{F}_{2}$, Recommended dose of fertilizer/ RDF (80-40-40 kg N-P $\mathrm{O}_{5}-\mathrm{K}_{2} \mathrm{O} / \mathrm{ha}$ ); $\mathrm{F}_{3}$, RDF + boron@1.5 kg/ha; F, RDF + sulphur @ 25 kg/ha; F5, RDF + boron @ 1.5 kg/ha + sulphur 
@ $25 \mathrm{~kg} / \mathrm{ha} ; \mathrm{F}_{6}, \mathrm{RDF}+$ farm yard manure @ 5 t/ha; $F_{7}, \mathrm{RDF}+$ vermicompost @ 5 t/ha] in the sub-plots. The experiment consisted of 21 treatment combinations replicated thrice. The hybrid sunflower variety 'Aditya' was grown as test crop (produced and marketed by IndoAmerican Hybrid Seeds India Private Limited) under irrigated medium land situation with good drainage facility. Seeds were sown@6 $\mathrm{kg} / \mathrm{ha}$ on $19^{\text {th }}$ November in year 1 and $20^{\text {th }}$ November in year 2, at a spacing of $60 \mathrm{~cm} \times$ $30 \mathrm{~cm}(55,555$ plants/ha). The net plot size was $4 \mathrm{~m} \times 3 \mathrm{~m}$. The nutrients $(\mathrm{NPK})$ were provided to the crop as per treatment details through urea $(46 \% \mathrm{~N})$, di-ammonium phosphate $\left(18 \% \mathrm{~N}\right.$ and $\left.46 \% \mathrm{P}_{2} \mathrm{O}_{5}\right)$, muriate of potash $\left(60 \% \quad \mathrm{~K}_{2} \mathrm{O}\right)$, zinc sulphate $\left(\mathrm{ZnSO}_{4}\right.$, $7 \mathrm{H}_{2} \mathrm{O}$ with $\left.11 \% \mathrm{~S}\right)$, Granubor ${ }^{\circledR}$ Natur (Disodium Tetraborate Pentahydrate; Granular with $15 \% \mathrm{~B})$, farm yard manure $(0.56 \% \mathrm{~N}$, $0.24 \% \quad \mathrm{P}_{2} \mathrm{O}_{5} \quad$ and $\left.0.59 \% \quad \mathrm{~K}_{2} \mathrm{O}\right) \quad$ and vermicompost $\left(1.6 \% \mathrm{~N}, 0.98 \% \mathrm{P}_{2} \mathrm{O}_{5}\right.$ and $1.1 \%$ $\mathrm{K}_{2} \mathrm{O}$ ) respectively. All $\mathrm{P}, \mathrm{K}, \mathrm{B}$ and $\mathrm{Zn}$ fertilizers were applied to the soil prior to sowing in each plot.

The $\mathrm{N}$ fertilizer was applied in three splits $50 \%$ before sowing, $25 \%$ at 30 DAS and $25 \%$ at 45 DAS. FYM and vermicompost were surface broadcasted during final land preparation (as basal). Diesel operated water lifting pump (5 HP) was used for 15 hours to irrigate the crop with 50 ha-mm water under each irrigations. Two hand weeding (HW) were done at 20 and 40 DAS to promote early crop growth, maintain a good crop canopy and keep the plots more or less weed free. As a prophylactic measure, Neemazal-T/S (Azadirachtin 1\% EC) was sprayed twice (35 and 42 DAS) @ $1 \mathrm{ml} /$ litre of water. In addition, Pride (Acetamiprid 20\% SP) was sprayed @ $3 \mathrm{~g} / 10$ litres of water at 50 DAS for controlling white fly. The plants were cut at the base after attaining harvest maturity (120 DAS). The capitula were sun dried for 2-3 days, and then seeds were separated.
Pearson's correlation coefficients were calculated to describe the degree and pattern of associations of observed traits in hybrid sunflower (cv. Aditya). Direct and indirect path coefficients were calculated for quantitative traits using the software MS Excel (version 2007, Microsoft Inc., WA, USA). For path analysis of quantitative traits, seed yield (SEY) was considered as response variable whereas plant height $(\mathrm{PH})$, leaf area index (LAI), total dry matter accumulation (TDMA), basal girth (BG), capitulum diameter (CD), number of filled seeds per capitulum (NFSC), weight of total seeds per capitulum (WTSC), weight of filled seeds per capitulum (WFSC), seed index (SI) and stalk yield (STY) were considered as causal variable. Finally, Canoco, a Fortran program version 4.5 (Ter Braak, 2003) was used to determine the association of observed parameters with irrigation and fertilization practices. Regression factor scores with respect to component loading for first two components were calculated and scatter diagram was drawn.

\section{Results and Discussion}

Pair-wise association between the assessed traits of tested cultivar through correlation study

Pearson correlation coefficients showing pairwise associations between the assessed traits of the tested hybrid sunflower cultivar are presented in Table 1. Among the phenotypic traits evaluated, significant and positive correlation were observed between $\mathrm{PH}$ and LAI $(r=0.66, p \leq 0.01)$, TDMA $(r=0.37, p \leq$ $0.01), \mathrm{CD}(\mathrm{r}=0.25, p \leq 0.01)$, WTSC $(\mathrm{r}=$ $0.22, p \leq 0.05)$, WFSC $(\mathrm{r}=0.23, p \leq 0.01)$ and SEY ( $\mathrm{r}=0.37, p \leq 0.01)$. The LAI showed significant $(p \leq 0.01)$ and positive correlation with TDMA $(\mathrm{r}=0.52), \mathrm{BG}(\mathrm{r}=0.38), \mathrm{CD}(\mathrm{r}=$ $0.31)$, NFSC $(r=0.23)$, WTSC $(r=0.29)$, WFSC $(r=0.36)$, SI $(r=0.29)$, SEY $(r=0.43)$ and STY $(r=0.19, p \leq 0.05)$. Significant $(p \leq$ 
$0.01)$ and positive correlations were also observed between TDMA with BG $(r=0.34)$, CD $(r=0.27)$, NFSC $(r=0.37)$, WTSC $(r=$ $0.38)$, WFSC $(r=0.37)$, SI $(r=0.42)$, SEY $(r$ $=0.52)$ and STY $(r=0.39)$. Similarly, BG was significantly $(p \leq 0.01)$ and positively correlated with CD $(\mathrm{r}=0.51)$, NFSC $(\mathrm{r}=$ $0.57)$, WTSC $(r=0.48)$, WFSC $(r=0.53)$, SI $(r=0.46)$, SEY $(r=0.61)$ and STY $(r=0.63)$. Significant $(p \leq 0.01)$ and positive correlation were observed between CD and NFSC ( $\mathrm{r}=$ $0.54)$, WTSC $(r=0.48)$, WFSC $(r=0.52)$, SI $(r=0.57)$, SEY $(r=0.50)$ and STY $(r=0.51)$. Also significant $(p \leq 0.01)$ and positive correlation were detected between NFSC and WTSC $(r=0.66)$, WFSC $(r=0.66)$, SI $(r=$ $0.45)$, SEY $(r=0.58)$ and STY $(r=0.53)$. Significant $(p \leq 0.01)$ and positive correlation were also observed between WTSC and WFSC $(r=0.89)$, SI $(r=0.39)$, SEY $(r=0.57)$ and STY $(r=0.44)$. Similarly WFSC was significantly $(p \leq 0.01)$ and positively correlated with SI $(r=0.44)$, SEY $(r=0.58)$ and STY $(r=0.41)$. Significant $(p \leq 0.01)$ and positive correlations were also observed between SI and SEY $(r=0.49)$ and STY $(r=$ 0.41). Finally, strong and significant correlation was detected between SEY and STY $(r=0.59, p \leq 0.01)$.

The strong relationships among the observed phenotypic characters in the present study indicated that these characters were governed by the same genetic system i.e. the characters were expected to be linked with each other and they should be given high priority during selection of hybrid genotypes of sunflower. Generally the greater positive associations of seed yield with total dry matter accumulation, basal girth, capitulum diameter, number of filled seed per capitulum, weight of filled seeds per capitulum and seed index (100-seed weight) suggests the prospects of improving seed yield of hybrid sunflower by concurrent improvement in all the above mentioned yield attributing characters.
Simple Person's correlation coefficient values of yield with plant nutrient uptake and available nutrient status of post-harvest soil are given in Table 2. The seed yield and stalk yield both had significant positive correlations with plant nutrient uptake and available nutrient status of post-harvest soil. It was observed that seed yield showed highest significant positive correlation with TNU ( $\mathrm{r}=$ $0.670, p \leq 0.01)$, closely followed by TBU ( $\mathrm{r}=$ $0.669, p \leq 0.01)$, compared to total uptake of other nutrients (TPU, TKU and TSU). The seed yield also had significant positive correlations with nutrient status of soil and greater value was obtained with $\mathrm{AN}$ ( $\mathrm{r}=$ $0.602, p \leq 0.01)$. Similarly, it was observed that stalk yield showed highest significant positive correlation with TSU $(\mathrm{r}=0.962, p \leq$ $0.01)$, closely followed by TNU ( $\mathrm{r}=0.933, p$ $\leq 0.01$ ), compared to total uptake of other nutrients (TPU, TKU and TBU). The stalk yield also had significant positive correlations with nutrient status of soil and greater value was obtained with AN ( $\mathrm{r}=0.690, p \leq 0.01)$. TSU showed highest significant positive correlation with TNU $(\mathrm{r}=0.909, p \leq 0.01)$, TPU ( $\mathrm{r}=0.911, p \leq 0.01)$, TKU $(\mathrm{r}=0.832, p$ $\leq 0.01)$ and TBU $(r=0.853, p \leq 0.01)$. With respect to nutrient status of post-harvest soil, AN had significant positive correlations with TNU ( $\mathrm{r}=0.657, p \leq 0.01)$, TPU ( $\mathrm{r}=0.771, p$ $\leq 0.01)$, TKU $(\mathrm{r}=0.575, p \leq 0.01)$, TBU $(\mathrm{r}=$ $0.665, p \leq 0.01)$ and TSU $(\mathrm{r}=0.770, \mathrm{p} \leq$ 0.01 ). It was observed that AN showed highest and lowest significant positive correlations with $\mathrm{AK}(\mathrm{r}=0.640, p \leq 0.01)$ and $\mathrm{AB}(\mathrm{r}=$ $0.221, p \leq 0.05)$. Similarly, AP showed highest and lowest significant positive correlations with $\mathrm{AK}(\mathrm{r}=0.316, \mathrm{p} \leq 0.01)$ and $\mathrm{AB} \quad(\mathrm{r}=0.222, p \leq 0.05)$. Results also indicated that there was significant positive correlation between $\mathrm{AB}$ and $\mathrm{AS}(\mathrm{r}=0.260, p$ $\leq 0.01)$.

Simple Person's correlation coefficient values of oil content with different qualitative traits 
are given in Table 3. The OC had significant positive correlations with LA $(\mathrm{r}=0.874, p \leq$ $0.01)$, OA $(\mathrm{r}=0.909, p \leq 0.01)$ and IV $(\mathrm{r}=$ $0.936, p \leq 0.01)$, while significant negative correlations was observed with PA $(\mathrm{r}=-0.905$, $p \leq 0.01)$, SA $(\mathrm{r}=-0.828, p \leq 0.01)$ and SV (r $=-0.929, p \leq 0.01)$. It was also observed that LA had significant positive correlations with $\mathrm{OA}(\mathrm{r}=0.893, p \leq 0.01)$ and IV $(\mathrm{r}=0.904, p$ $\leq 0.01$ ), while significant negative correlations was observed with PA ( $\mathrm{r}=-0.786, p \leq 0.01)$, $\mathrm{SA}(\mathrm{r}=-0.910, p \leq 0.01)$ and $\mathrm{SV}(\mathrm{r}=-0.854, p$ $\leq 0.01)$. Results also indicated that there was highly significant positive correlation only between OA and IV ( $\mathrm{r}=0.927, p \leq 0.01)$. Whereas, OA had significant negative correlations with PA $(\mathrm{r}=-0.889, p \leq 0.01)$, SA $(\mathrm{r}=-0.778, p \leq 0.01)$ and $\mathrm{SV}(\mathrm{r}=-0.895, p \leq$ 0.01). The PA had significant positive correlations with SA $(\mathrm{r}=0.688, p \leq 0.01)$ and $\mathrm{SV}$ ( $\mathrm{r}=0.917, p \leq 0.01)$, while significant negative correlations was observed only with IV ( $\mathrm{r}=-0.901, p \leq 0.01)$. SA had significant positive and negative correlations with $\mathrm{SV}(\mathrm{r}=$ $0.783, p \leq 0.01)$ and IV $(\mathrm{r}=-0.827, p \leq 0.01)$, respectively. Results also indicated that there was highly significant negative correlation only between SV and IV $(\mathrm{r}=-0.919, p \leq$ $0.01)$.

Splitting the correlation coefficient into direct and indirect influences of various traits of hybrid sunflower through path coefficient analysis

With the aim of analyzing the genetic correlations further and splitting the correlation coefficient into direct and indirect influences of different attributes, path coefficient technique was employed. It, therefore, warrants an acute study of attributes those affect a certain correlation and can be advantageous in preparing a competent selection approach (Scheiner et al., 2000). Results of the path coefficient with hybrid sunflower seed yield as the response variable are summarized in Table 4. Values of direct effects were $<1$, indicating that inflation due to multi-collinearity was low. Among the growth and yield components, BG (0.612) followed by NFSC (0.579) and WFSC (0.577) exhibited highly positive direct effects on seed yield of hybrid sunflower (Table 4). The direct selection for these three characters could be beneficial for yield improvement of hybrid sunflower since these characters also showed positive correlation with seed yield. However, other growth attributes (PH, LAI, TDMA and CD) and yield determining traits (WTSC and SI) exerted comparatively low positive direct effects on seed yield of hybrid sunflower. Hence selection based on these characters will marginally improve seed yield of hybrid sunflower. Residual effect was low (0.365) suggesting inclusion of maximum seed yield influencing characters of hybrid sunflower in the present analysis.

Path coefficient analysis is increasingly being used in plant breeding (Samonte et al., 1998). There are scanty of studies on agronomic traits in hybrid sunflower to identify the preeminent selection standards linked to increased seed yield and the other attributes that influence it. In the present study, the observed three specific traits (BG, NFSC and WFSC) with superior genetic variability, heritability, higher expected genetic gain under selection and their correlation with seed yield can consistently be employed for enhancement of seed yield via ancillary selection (Table 5).

Assessment of the relationship between dependent and independent variables through multiple step-wise regression analysis

Multiple regression analysis was used to assess the relationships between one dependent variable and many independent variables. 
Table.1 Phenotypic correlation coefficients between seed yield and observed traits in hybrid sunflower cv. Aditya (based on mean values of two years)

\begin{tabular}{|c|c|c|c|c|c|c|c|c|c|c|c|}
\hline Traits & PH & LAI & TDMA & BG & CD & NFSC & WTSC & WFSC & SI & SEY & STY \\
\hline PH & 1.000 & $.662^{* *}$ & $.365^{* *}$ & .153 & $.254^{* *}$ & .109 & $.224^{*}$ & $.230^{* *}$ & .063 & $.371^{* *}$ & .123 \\
\hline LAI & & 1.000 & $.517^{* *}$ & $.382^{* *}$ & $.309^{* *}$ & $.231^{* *}$ & $.292^{* *}$ & $.357^{* *}$ & $.286^{* *}$ & $.431^{* *}$ & $.190^{*}$ \\
\hline TDMA & & & 1.000 & $.338^{* *}$ & $.271^{* *}$ & $.370^{* *}$ & $.378^{* *}$ & $.372^{* *}$ & $.416^{* *}$ & $.516^{* *}$ & $.391^{* * *}$ \\
\hline BG & & & & 1.000 & $.507^{* *}$ & $.566^{* *}$ & $.477^{* *}$ & $.533^{* *}$ & $.462^{* *}$ & $.612^{* *}$ & $.626^{* *}$ \\
\hline CD & & & & & 1.000 & $.454^{* *}$ & $.478^{* *}$ & $.519^{* *}$ & $.566^{* *}$ & $.504^{* *}$ & $.513^{* * *}$ \\
\hline NFSC & & & & & & 1.000 & $.657^{* *}$ & $.657^{* *}$ & $.451^{* *}$ & $.579^{* *}$ & $.526^{* *}$ \\
\hline WTSC & & & & & & & 1.000 & $.888^{* *}$ & $.395^{* *}$ & $.565^{* *}$ & $.438^{* *}$ \\
\hline WFSC & & & & & & & & 1.000 & $.444^{* *}$ & $.577^{* *}$ & $.407^{* *}$ \\
\hline SI & & & & & & & & & 1.000 & $.498^{* *}$ & $.414^{* * *}$ \\
\hline SEY & & & & & & & & & & 1.000 & $.596^{* *}$ \\
\hline STY & & & & & & & & & & & 1.000 \\
\hline
\end{tabular}

Notes: $\mathrm{PH}=$ Plant height at $100 \mathrm{DAS}$ in $\mathrm{cm}, \mathrm{LAI}=$ Leaf area index at $75 \mathrm{DAS}, \mathrm{TDMA}=$ Total dry matter accumulation at $100 \mathrm{DAS}$ in $\mathrm{g} / \mathrm{m}^{2}, \mathrm{BG}=\mathrm{Basal}$ girth at harvest in $\mathrm{cm}, \mathrm{CD}=$ Capitulum diameter at harvest in $\mathrm{cm}, \mathrm{NFSC}=$ Number of filled seeds/ capitulum, WTSC $=$ Weight of total seeds/ capitulum in $\mathrm{g}$, WFSC $=$ Weight of filled seeds/ capitulum in $\mathrm{g}, \mathrm{SI}=$ Seed index in $\mathrm{g}, \mathrm{SEY}=$ Seed yield in $\mathrm{t} / \mathrm{ha}, \mathrm{STY}=\mathrm{Stalk}$ yield in $\mathrm{t} / \mathrm{ha}$

$*$ and $* *$ indicates correlation is significant at 5.0 and $1.0 \%$ level of significance, respectively. 
Table.2 Relationships (r) among hybrid sunflower yield and plant nutrient uptake and available nutrient status in post-harvest soil

\begin{tabular}{|c|c|c|c|c|c|c|c|c|c|c|c|c|}
\hline Traits & SEY & STY & TNU & TPU & TKU & TBU & TSU & $\mathbf{A N}$ & $\mathbf{A P}$ & $\mathbf{A K}$ & $\mathbf{A B}$ & AS \\
\hline SEY & 1.000 & $.596^{* * *}$ & $.670^{* *}$ & $.618^{* *}$ & $.561^{* *}$ & $.669^{* *}$ & $.662^{* *}$ & $.602^{* *}$ & $.329^{* *}$ & $.337^{* *}$ & $.352^{* *}$ & $.340^{* *}$ \\
\hline STY & & 1.000 & $.933^{* *}$ & $.874^{\text {*** }}$ & $.856^{* *}$ & $.857^{* *}$ & $.962^{* *}$ & $.690^{* *}$ & $.434^{* *}$ & $.573^{* *}$ & $.301^{* *}$ & $.478^{* *}$ \\
\hline$\overline{T N U}$ & & & 1.000 & $.846^{\text {*** }}$ & $.859^{* * *}$ & $.826^{* *}$ & $.909^{* *}$ & $.657^{* *}$ & $.373^{* *}$ & $.463^{* *}$ & $.357^{* *}$ & $.480^{* *}$ \\
\hline TPU & & & & 1.000 & $.818^{* *}$ & $.812^{* *}$ & $.911^{* * *}$ & $.771^{* *}$ & $.471^{* *}$ & $.570^{* *}$ & $.191^{*}$ & $.454^{* *}$ \\
\hline TKU & & & & & 1.000 & $.763^{* *}$ & $.832^{* *}$ & $.575^{* *}$ & $.381^{* *}$ & $.463^{* *}$ & $.302^{* *}$ & $.420^{* *}$ \\
\hline$\overline{\text { TBU }}$ & & & & & & 1.000 & $.853^{* *}$ & $.665^{* *}$ & $.496^{* *}$ & $.462^{* *}$ & $.321^{* * *}$ & $.317^{* *}$ \\
\hline TSU & & & & & & & 1.000 & $.770^{* *}$ & $.446^{* *}$ & $.604^{* *}$ & $.320^{* *}$ & $.554^{* *}$ \\
\hline $\mathbf{A N}$ & & & & & & & & 1.000 & $.481^{* *}$ & $.640^{* * *}$ & $.221^{*}$ & $.395^{* *}$ \\
\hline $\mathbf{A P}$ & & & & & & & & & 1.000 & $.316^{* * *}$ & $.222^{*}$ & .138 \\
\hline $\mathbf{A K}$ & & & & & & & & & & 1.000 & .174 & $.378^{* *}$ \\
\hline $\mathbf{A B}$ & & & & & & & & & & & 1.000 & $.260^{* * *}$ \\
\hline $\mathbf{A S}$ & & & & & & & & & & & & 1.000 \\
\hline
\end{tabular}

SEY and STY represent seed and stalk yield, respectively; TNU, TPU, TKU, TBU and TSU represent total N, P, K, B and S uptake, respectively; AN, AP, AK, $\mathrm{AB}$ and $\mathrm{AS}$ represent available N, P, K, B and S content in post-harvest soil, respectively.

$*$ and $* *$ indicates correlation is significant at 5.0 and $1.0 \%$ level of significance, respectively.

Table.3 Relationship among hybrid sunflower oil content and different qualitative traits

\begin{tabular}{|l|c|c|c|c|c|c|c|c|}
\hline Traits & OIC & LA & OA & PA & SA & SV & IV \\
\hline OIC & 1.000 & $.874^{* *}$ & $.909^{* *}$ & $-.905^{* * *}$ & $-.828^{* *}$ & $-.929^{* *}$ & $.936^{* *}$ \\
\hline LA & & 1.000 & $.893^{* *}$ & $-.786^{* *}$ & $-.910^{* *}$ & $-.854^{* *}$ & $.904^{* *}$ \\
\hline OA & & & 1.000 & $-.889^{* *}$ & $-.778^{* *}$ & $-.895^{* *}$ & $.927^{* *}$ \\
\hline PA & & & & 1.000 & $.688^{* *}$ & $.917^{* *}$ & $-.901^{* *}$ \\
\hline SA & & & & & 1.000 & $.783^{* *}$ & $-.827^{* *}$ \\
\hline SV & & & & & & 1.000 & $-.919^{* *}$ \\
\hline IV & & & & & & 1.000 \\
\hline
\end{tabular}

OIC, LA, OA, PA, SA, SV and IV represent oil content, linoleic acid content, oleic acid content, palmitic acid content, stearic acid content, saponification value and iodine value in hybrid sunflower oil, respectively.

** indicate correlation is significant at $1.0 \%$ level of significance, respectively. 
Table.4 Direct (diagonal) and indirect effects of ten growth and yield components on seed yield of hybrid sunflower cv. Aditya at phenotypic level (based on mean value of two years)

\begin{tabular}{|c|c|c|c|c|c|c|c|c|c|c|c|}
\hline Traits & PH & LAI & TDMA & BG & CD & NASC & WTSC & WFSC & SI & STY & $\begin{array}{c}\text { Total } \\
\text { correlation } \\
\text { with seed yield }\end{array}$ \\
\hline PH & 0.205 & .049 & .004 & .002 & -.020 & .004 & -.045 & .043 & .000 & .071 & $.371^{* *}$ \\
\hline LAI & .135 & 0.074 & .005 & .005 & -.024 & .009 & -.058 & .067 & .002 & .110 & $.431^{* *}$ \\
\hline TDMA & .075 & .038 & 0.010 & .004 & -.021 & .015 & -.076 & .070 & .003 & .226 & $.516^{* *}$ \\
\hline$\overline{\mathrm{BG}}$ & .031 & .028 & .004 & 0.012 & -.039 & .023 & -.095 & .100 & .003 & .362 & $.612^{* *}$ \\
\hline $\mathrm{CD}$ & .052 & .023 & .003 & .006 & 0.077 & .018 & -.096 & .098 & .004 & .296 & $.504^{* *}$ \\
\hline NFSC & .022 & .017 & .004 & .007 & -.035 & 0.041 & -.131 & .124 & .003 & .304 & $.579^{* *}$ \\
\hline WTSC & .046 & .022 & .004 & .006 & -.037 & .027 & -0.200 & .167 & .003 & .253 & $.565^{* *}$ \\
\hline WFSC & .047 & .027 & .004 & .006 & -.040 & .027 & -.178 & 0.188 & .003 & .235 & $.577^{* *}$ \\
\hline SI & .013 & .021 & .004 & .006 & -.043 & .018 & -.079 & .084 & 0.006 & .239 & $.498^{* *}$ \\
\hline STY & .025 & .014 & .004 & .008 & -.039 & .021 & -.088 & .077 & .003 & 0.578 & $.596^{* *}$ \\
\hline
\end{tabular}

Notes: $\mathrm{PH}=$ Plant height at $100 \mathrm{DAS}$ in $\mathrm{cm}, \mathrm{LAI}=$ Leaf area index at $75 \mathrm{DAS}, \mathrm{TDMA}=$ Total dry matter accumulation at $100 \mathrm{DAS}$ in $\mathrm{g} / \mathrm{m}^{2}, \mathrm{BG}=\mathrm{Basal}$ girth at harvest in $\mathrm{cm}, \mathrm{CD}=$ Capitulum diameter at harvest in $\mathrm{cm}, \mathrm{NFSC}=$ Number of filled seeds $/$ capitulum, WTSC $=$ Weight of total seeds/ capitulum in $\mathrm{g}, \mathrm{WFSC}=$

Weight of filled seeds/ capitulum in g, SI = Seed index in g, SEY = Seed yield in t/ha, STY = Stalk yield in t/ha; Residual effect $=0.365$.

** indicate correlation is significant at $1.0 \%$ level of significance. 
Table.5 The first four ordinates axis of CCA for explaining the variance (\%) in the weighted averages for dominance of observed parameters with respect to the irrigation and fertilizer variables

\begin{tabular}{|l|l|l|l|l|}
\hline Axis & 1 & 2 & 3 & 4 \\
\hline Eigen values & 0.008 & 0.001 & 0.017 & 0.006 \\
\hline Independent-Dependent set correlations & 0.751 & 0.375 & 0.000 & 0.000 \\
\hline Cumulative percentage variance & & & & \\
\hline Dependent set & 18.9 & 20.3 & 59.4 & 73.0 \\
\hline Independent-Dependent set relation & 93.1 & 100.0 & 0.0 & 0.0 \\
\hline Sum of all eigen values & 0.044 & & & \\
\hline Sum of all canonical eigen values & 0.009 & & & \\
\hline
\end{tabular}

Fig.1 CCA ordination diagram of hybrid sunflower (cv. Aditya) grown in West Bengal. Text in red ink-bold represented by arrow depict two variables (irrigation and fertilizer), while text in upper case-italics represents the observed parameters with triangle symbol

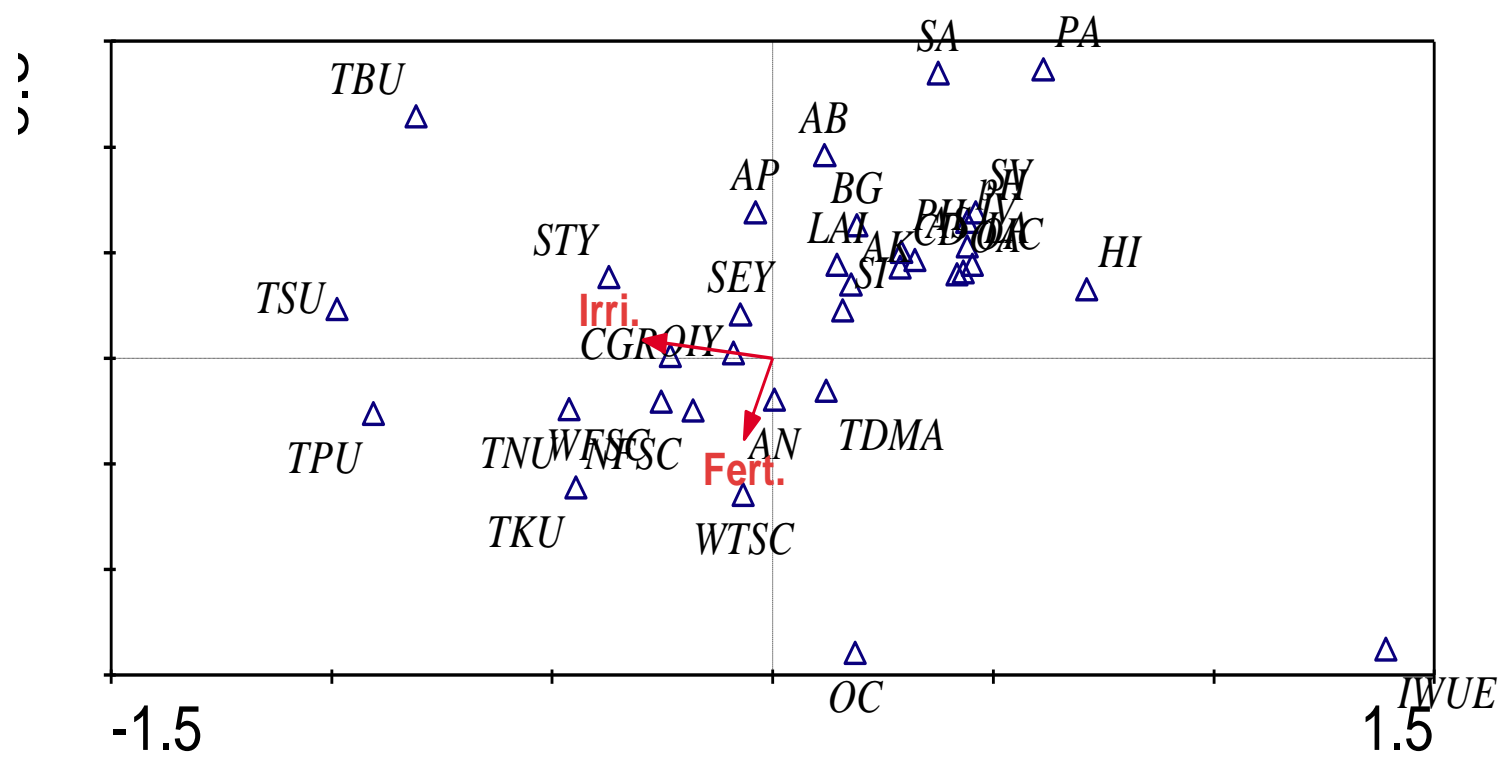

All the observed parameters were used as independent variables in the multiple regression analysis.

The following standard regression equation showed that independent variables like total $\mathrm{N}$ uptake, plant height, available $\mathrm{N}$, weight of filled seeds/capitulum and seed index (100seed weight) had positive significant relationship with seed yield (dependent variable).
Therefore, higher values of these observed variables would increase seed yield.

Seed yield $=-0.335+0.005$ total $\mathrm{N}$ uptake ${ }^{* *}+$ 0.003 plant height ${ }^{* *}+0.003$ available $\mathrm{N}^{* *}+$ 0.004 weight of filled seeds/ capitulum ${ }^{* *}+$ 0.062 seed index ${ }^{*}$

Where, ${ }^{*}$ and ${ }^{* *}$ indicates correlation is significant at 5.0 and $1.0 \%$ level of significance; $R^{2}=0.607$ 
Assessment of the relationship between two sets of variables through canonical correspondence analysis (CCA)

A canonical correspondence analysis (CCA) was used to ordinate the data on observed parameters in relation to the irrigation and fertilizer variables. The first two ordinates axes explained $100 \%$ of the total variance in the weighted averages for dominance of observed parameters with respect to the irrigation and fertilizer variables. Figure 1 indicates greater influence of irrigation frequency on TBU, TSU, STY, AP, SEY, CGR and OIY of hybrid sunflower, while fertilizer level exhibited greater influence on TPU, TNU, TKU, WFSC, NFSC, AN and WTSC. Several of the most observed variables were located near the origin of the ordination diagram (Figure 1), indicating the ability of the sunflower hybrid to thrive under very diverse agro-ecosystem. In the CCA biplot (Ter Braak and Prentice, 1988), the length of arrows indicates the importance of the factors (longer arrows $=$ more important). Accordingly, among the two variables considered, irrigation was more important than fertilizer, which had a short arrow.

The greater positive associations of seed yield with total dry matter accumulation, basal girth, capitulum diameter, number of filled seed per capitulum, weight of filled seeds per capitulum and seed index (100-seed weight) suggests the prospects of improving seed yield of hybrid sunflower by concurrent improvement in all the above mentioned yield attributing characters. Among the growth and yield components, BG followed by NFSC and WFSC exhibited highly positive direct effects on seed yield of hybrid sunflower. The direct selection for these three characters could be beneficial for yield improvement of hybrid sunflower since these characters also showed positive correlation with seed yield. The standard regression equation showed that independent variables like total $\mathrm{N}$ uptake, plant height, available $\mathrm{N}$, weight of filled seeds/capitulum and seed index (100-seed weight) had positive significant relationship with seed yield (dependent variable). The first two ordinates axis of CCA explained $100 \%$ of the total variance in the weighted averages for dominance of observed parameters with respect to the irrigation and fertilizer variables, while irrigation was more important than fertilization.

\section{References}

Banerjee H., Dutta, S.K., Pramanik, S.J., Ray, $\mathrm{K}$, Phonglosa, A. and Bhattacharyya, K. (2014). Productivity and profitability of spring planted sunflower hybrid with nitrogen, phosphorus and potassium fertilizer. Annals of Plant and Soil Research, 16(3): 250-256.

Bhattacharyya, K., Mandal, J., Banerjee, H., Alipatra, A., Ray, K. and Phonglosa, A. (2015). Boron fertilization in Sunflower (Helianthus annuus L.) in an Inceptisol of West Bengal, India. Communications in Soil Science and Plant Analysis, 46(4): 528-544.

Hassan, S.M.F., Iqbal, M.S., Rabbani, G., Naeem-ud-Din, Shabbir, G., Riaz, M. and Noorka, I.R. (2013). Correlation and path analysis for yield and yield components in sunflower (Helianthus annus L.). African Journal of Biotechnology, 12(16): 1968-1971.

Indiastat (2017). Season wise Area, Production and Yield of Sunflower in India (1970-1971 to 2016-2017-2 ${ }^{\text {nd }}$ Advance Estimates). Available at URL: https://www.indiastat.com/table/agricult ure2/sunflower/19581/17394/data.apsx (Accessed on 5th May, 2017).

Mashilo, J., Shimelis, H. and Odindo, A. (2016). Correlation and path coefficient analysis of qualitative and quantitative traits in selected bottle gourd landraces. 
Acta Agriculturae Scandinavica-Section $B$ (Soil \& Plant Science), 66(7): 558569.

Moitra, A., Puste, A.M., Mandal, T.K., Gunri, S.K., Banerjee, H. and Pramanik, B.R. (2012). Yield, water use and economics of summer sunflower (Helianthus annuus L.) as influenced by irrigation and integrated nutrient management. World Journal of Science and Technology, 2(7): 81-86.

Ramulu, Krishnamurthy, N., Jayadeva, K.M., Venkatesha, M.M. and Ravi Kumar, H.S. (2011). Seed yield and nutrients uptake of sunflower (Helianthus annuus L.) as influenced by different levels of nutrients under irrigated condition of eastern dry zone of Karnataka, India. Plant Archives, 11(2): 1061-1066.

Samonte, S.O.P.B., Wilson, L.T. and McClung, A.M. (1998). Path analysis of yield and yield related traits of fifteen diverse rice genotypes. Crop Science, 38: 1130-1136.

Scheiner, S.M., Mitchell, R.J. and Callahan, H.S. (2000). Using path analysis to measure natural selection. Journal of Evolutionary Biology, 13: 423-433.

Shimelis, H. and Hugo, A. (2011). Determination of selection criteria for seed yield and seed oil content in Vernonia (Vernonia galamensis var. ethiopica). Industrial Crops and Products, 33: 436-439.

Ter Braak, C.J.F. (2003). Progam CANOCO Version 4.5A (1988-2003) Biometrics quantitative methods in the life and earth sciences. Netherlands: Plant Research International, Wageningen University and Research Centre, Wageningen.

Ter Braak, C.J.F. and Prentice, I.C. (1988). A theory of gradient analysis. Adv. Ecol. Res., 18: 271-317.

\section{How to cite this article:}

Ayon Alipatra, Hirak Banerjee and Debasis Mazumdar. 2018. Correlation and Path Coefficient Analysis of Quantitative and Qualitative Traits in Hybrid Sunflower (Helianthus annuиs L.). Int.J.Curr.Microbiol.App.Sci. 7(10): 568-578. doi: https://doi.org/10.20546/ijcmas.2018.710.063 